\title{
Long-term evaluation of apical root resorption after orthodontic treatment using periapical radiography and cone beam computed tomography
}

\author{
Jairo Curado de Freitas , Olavo César Porto Lyra², Ana Helena Gonçalves de Alencar ${ }^{3}$, Carlos Estrela ${ }^{4}$
}

Objective: To evaluate the frequency of Apical Root Resorption (ARR) after orthodontic treatment at 52-288 months using periapical radiography (PR) and cone beam computed tomography (CBCT). Methods: Radiographic images obtained from 58 patients, before $\left(\mathrm{T}_{1}\right)$ and after orthodontic treatment $\left(\mathrm{T}_{2}\right)$, and following 52-288 months of treatment were analyzed by three members of the Brazilian Board of Orthodontics. Apical structures were evaluated by PR images $\left(\mathrm{T}_{2}\right.$ and $\left.\mathrm{T}_{3}\right)$, using Levander and Malmgren scores. The presence of ARR on CBCT images were detected only at $\mathrm{T}_{3}$. The Kolmogorov-Smirnov test was used for statistical analyses, and the level of significance was set at 5\%. Kappa statistics determined interobserver agreement. Results: The more frequent ARR were with scores 1 in $\mathrm{T}_{2}(51.6 \%)$ and $\mathrm{T}_{3}(53.1 \%)$, when evaluated by PR ( $\left.\mathrm{p}>0.05\right)$. When compared the frequencies of ARR in $\mathrm{T}_{3}$ among PR and CBCT images, the differences were significant for maxillary and mandibular pre-molar groups, and for mandibular molar group ( $p>0.05)$. The teeth with highest frequency of ARR presence using CBCT images were maxillary lateral incisors (94.5\%) and mandibular central incisors (87.7\%), while the premolars showed the lowest frequency. The CBCT images showed that the teeth involved in orthodontic treatment with extraction present higher ARR frequency $(\mathrm{p}<$ 0.05). Conclusion: PR showed more frequency of ARR in posterior teeth groups when compared with CBCT images. ARR did not change in long-term post treatment.

Keywords: Tooth resorption. Cone beam computed tomography. Corrective orthodontics.

Objetivo: avaliar a frequência de reabsorção radicular apical (RRA) após tratamento ortodôntico, em longo prazo, por meio de imagens de radiografia periapical (RP) e tomografia computadorizada de feixe cônico (TCFC). Métodos: as imagens radiográficas obtidas de dentes de 58 pacientes, antes $\left(T_{1}\right)$, após o tratamento ortodôntico $\left(T_{2}\right)$ e decorridos pelo menos 52 meses do tratamento $\left(\mathrm{T}_{3}\right)$, foram analisadas por três examinadores, membros do Board Brasileiro de Ortodontia e Ortopedia Facial. As estruturas apicais foram avaliadas por meio de imagens de RP $\left(\mathrm{T}_{2}\right.$ e $\left.\mathrm{T}_{3}\right)$, utilizando o sistema de escores de Levander e Malmgren modificado. A presença de RRA nas imagens tomográficas obtidas em $\mathrm{T}_{3}$ foi detectada por um especialista em radiologia com experiência em TCFC. Os dados foram estatisticamente analisados pelo teste de Kolmogorov-Smirnov, com nível de significância de 5\%. O teste kappa determinou o nível de concordância entre os observadores. Resultados: as RRAs mais frequentes foram as de escore $1 \mathrm{em} \mathrm{T}_{2}(51,6 \%)$ e em $\mathrm{T}_{3}(53,1 \%)$, quando avaliadas por RPs ( $p>0,05)$. Quando comparadas as frequências de RRAs em $\mathrm{T}_{3}$, entre imagens de RP e de TCFC, a diferença foi estatisticamente significativa para o grupo de pré-molares da maxila e da mandíbula, e de molares mandibulares. Os dentes que apresentaram maior frequência de RRA quando analisados por meio de imagens de TCFC, foram os incisivos laterais superiores $(94,5 \%)$ e os centrais inferiores $(87,7 \%)$, enquanto os de menor frequência foram os pré-molares. As imagens de TCFC mostraram que os dentes envolvidos em tratamentos ortodônticos com extrações apresentaram maior frequência de RRA $(p<0,05)$. Conclusão: as radiografias periapicais mostraram maior frequência de RRAs que as imagens de TCFC para os grupos de pré-molares e molares, não evidenciando alteração em longo prazo.

Palavras-chave: Reabsorção da raiz. Tomografia computadorizada de feixe cônico espiral. Ortodontia corretiva.

\footnotetext{
${ }^{1} \mathrm{PhD}$ in Health Sciences, UFG.

${ }^{2} \mathrm{MSc}$ in Health Sciences, UFG.

${ }^{3}$ Post-doc in Endodontics, Cardiff University. Professor of Endodontics, School of Dentistry, UFG.

${ }^{4}$ Full Professor in Endodontics, USP. Professor of Endodontics, School of Dentistry, UFG.

" The authors report no commercial, proprietary or financial interest in the products or companies described in this article.
}

How to cite this article: Freitas JC, Lyra OCP, Alencar AHG, Estrela C. Longterm evaluation of apical root resorption after orthodontic treatment using periapical radiography and cone beam computed tomography. Dental Press J Orthod. 2013 July-Aug;18(4):104-12.

Submitted: May 06, 2011 - Revised and accepted: December 27, 2011

Contact address: Jairo Curado de Freitas

Praça Universitária, S/N - Setor Universitário - Goiânia/GO, Brazil

CEP: 74605-220 - E-mail: curadojf@terra.com.br 


\section{INTRODUCTION}

Apical root resorption may occur after orthodontic tooth movement. Its etiology is multifactorial and may be associated with individual biological variability, genetic predisposition, effect of mechanical factors, root morphology, and tooth injuries sustained before orthodontic treatment. ${ }^{1-6}$

Root resorption associated with orthodontic tooth movement is classified as inflammatory because it results from inflammation of the apical periodontium and the consequent destruction of tooth structures caused by clastic activity. ${ }^{7}$ Clinical relevance is not often mentioned when the rate of ARR is low. However, in severe ARR, structural tooth changes may result from an unfavorable combination of factors, such as anatomic, physiological and genetic variations. ${ }^{8,9,10}$ The understanding of the pathological mechanisms of radicular resorptions due to orthodontic treatment may help to establish accurate treatment plans.

Clinically, periapical radiographs are often used for diagnosis, treatment planning and follow-up. The revolution of information technology in health investigations started with computed tomography (CT), which has been used for planning, diagnosis, treatment and prognosis of several diseases. ${ }^{11,12}$ Cone beam computed tomography (CBCT) is a recently developed technology ${ }^{13,14}$ with important applications in research, clinical dentistry in general, and orthodontics in particular. ${ }^{15-18}$

A longitudinal prospective study ${ }^{19}$ of the progression of ARR associated with orthodontic treatment using PR showed that central incisors do not continue to lose root length during the retention phase. Furthermore, no association with gender, age, overbite, overjet, headgear use, or intrusion mechanics was found. ARR was greater in patients that had undergone extractions.

Reukers et $\mathrm{al}^{20}$ used digitally reconstructed images of maxillary incisors and found that ARR prevalence was $63 \%$ in the group of incisors. Relevant root shortening was found in only a few cases. ${ }^{10,20}$ In another study, orthodontically induced ARR was evaluated using panoramic radiography and $\mathrm{CBCT}$, and results showed that ARR was found in $69 \%$ of the teeth when CBCT scans were used and in 44\% when panoramic radiography was the imaging method. ${ }^{21}$
As the application of CBCT in orthodontics seems promising, it may become a useful tool for the long-term follow up of patients that may develop ARR in association with orthodontic tooth movement in different tooth groups. However, few studies have focused on that use of CBCT. This study evaluated ARR at 52 to 288 months after treatment using periapical radiography and cone beam computed tomography. The null hypothesis was that there was no difference in apical root resorption frequencies detected by periapical radiography and cone beam computed tomography.

\section{MATERIAL AND METHODS}

Patients

Fifty-eight patients, 28 male and 30 female (1,392 teeth) were selected in a database search of a private orthodontic clinic in Goiânia, GO, Brazil. Inclusion criteria were: Complete orthodontic records, radiographs, pictures, plaster models, and orthodontic treatment completed at least 52 months before. Only patients whose radiographs showed high quality were included, and no patient had any history of retreatment. Time since treatment completion was up to 52 months, and patient mean age was 12 years and 4 months $(\mathrm{SD}=2.31$ ).

All the patients had been treated using edgewise mechanics by the same orthodontist and were invited to return for a follow-up examination, which included a full mouth set of periapical radiographs and CBCT scanning. The study was approved by the local Ethics in Research Committee (UFG, Prot. \#169/2008).

\section{Imaging methods}

Periapical radiographs were acquired using a Spectro 70X Dental X-ray unit (Dabi Atlante, Ribeirão Preto, SP, Brazil) at $70 \mathrm{kV}, 8 \mathrm{~mA}, 0.8 \mathrm{~mm} \times 0.8 \mathrm{~mm}$ focal spot, using Kodak Insight film (Eastman Kodak Co, Rochester, NY, USA), using bisector technique with position indicating device and exposure time in accordance with the region imaged. All films were processed automatically and developed using standard methods (Peri-Pro II, Air techniques, NY,USA).

CBCT images were acquired with a first generation i-CAT Cone Beam 3D imaging system (Imaging Sciences International, Hatfield, PA, USA). The vol- 


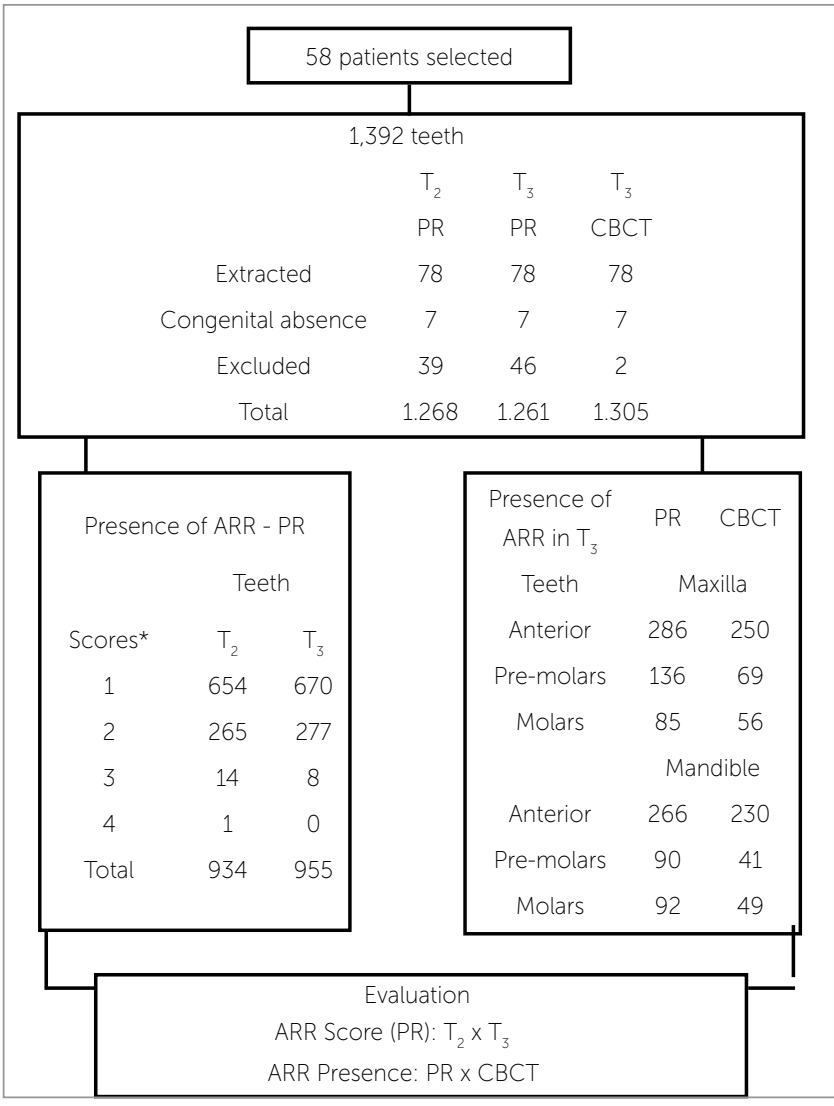

Figure 1 - Distribution of teeth according to presence or absence of ARR (Source: modified from Levander and Malmgren ${ }^{2}$ ).

umes were reconstructed at $0.2 \times 0.2 \times 0.2 \mathrm{~mm}$ voxel size. The tube voltage was $120 \mathrm{kVp}$, and the current, $3.8 \mathrm{~mA}$. Exposure time was 40 seconds. Images were examined using the scanner proprietary software (Xoran 3.1.62; Xoran Technologies, Ann Arbor, MI, USA) in a PC workstation running Microsoft Windows XP professional SP-2 (Microsoft Corp., Redmond, WA, USA), Intel ${ }^{\circledR}$ Core $^{\mathrm{TM}} 2$ Duo-6300 $1.86 \mathrm{GHz}$ (Intel Corporation, Santa Clara, CA, USA), NVIDIA GeForce 6200 turbo cache videocard (NVIDIA Corporation, Santa Clara, CA, USA) and an EIZO - Flexscan S2000 monitor at a resolution of $1600 \times 1200$ pixels (Eizo Nanao Corporation Hakusan, Ishikawa, Japan). The program tools permitted the evaluation of each tooth in three dimensions.

\section{Evaluation methods}

Periapical radiographs were analyzed at three time points: $T_{1}$ - before fixed orthodontic treatment; $\mathrm{T}_{2}$ - after fixed orthodontic treatment; $\mathrm{T}_{3}-$ at 52 to 288 months after treatment. Three members of the Brazilian Board of Orthodontics individually evaluated all images of PR in all teeth (except second and third molars) to detect ARR. The teeth with periapical lesions, traumatism history, and impossibility of diagnosis due to image overlapping and incomplete rhizogenes were excluded. The high number of teeth with incomplete apexes hindered the evaluation of apical structures in $\mathrm{T}_{1}$. To evaluate interexaminer reliability, $10 \%$ of the sample was examined.

Levander and Malmgren ${ }^{2}$ modified scoring system was used to evaluate ARR. Root apexes were classified into 5 levels of root resorption: $0=$ no root resorption; $1=$ irregular root outline; $2=$ apical root resorption, less than $2 \mathrm{~mm} ; 3=$ apical root resorption, from $2 \mathrm{~mm}$ to one third of the original root length; $4=$ apical root resorption exceeding one third of original root length. The radiographs were mounted on slit sheets of cardboard and examined in a darkened room using a light box (Medalight LP-300, Universal Electronics Ind., NY, USA) at $3 \mathrm{X}$ magnification.

The CBCT images obtained in $\mathrm{T}_{3}$ were evaluated by a radiology specialist with 5 years of training. CBCT was used only at $T_{3}$ because this imaging diagnostic tool was not available at the other time points.

The analysis of apical region was performed in a dynamic way into different plans (axial and cross-sectional). The thickness slices varied between 1 and $1.5 \mathrm{~mm}$.

ARR presence or absence in PR and CBCT images were evaluated in all dental groups. In teeth with more than one root, the most resorbed root was selected to determine the score for that tooth.

The expected initial number of teeth was 1,392; extracted and congenitally absent teeth and teeth whose images had superposed structures (Fig 1) were excluded. The number of teeth involved or not with ARR was recorded.

The Kolmogov-Smirnov test was used to evaluate the data. The level of significance was set at 5\%. Kappa statistics was used to determine interobserver agreement according to the study methods. 


\section{RESULTS}

From all 58 patients, 40 had been classified, at the beginning of orthodontic treatment as Class I; 14 patients classified as Class II, division 1; 2 patients classified as Class II, division 2; 2 patients classified as Class III. Forty-nine patients used some type of intermaxillary elastics. The mean duration of treatment was 22.9 months (SD = 6.72).

The distribution of teeth in sample, showing the presence or absence of ARR, is presented in Figure 1. The radiographic images of 1,268 teeth were analyzed in $\mathrm{T}_{2}, 1,261$ in $\mathrm{T}_{3}$, and 1,305 CBCT images in $\mathrm{T}_{3}$.

The frequency of ARR by PR after orthodontic treatment $\left(\mathrm{T}_{2}\right)$ and 52-288 months $\left(\mathrm{T}_{3}\right)$ is shown in Table 1. ARR more frequent score was 1 , presenting $51.6 \%$ in $\mathrm{T}_{2}$, and $53.1 \%$ in $\mathrm{T}_{3}$. There was no significant statistical difference between $\mathrm{T}_{2}$ and $\mathrm{T}_{3}$, when evaluated by PR, in none of the scores.

Kappa value used to determine interobserver agreement according to modified Levander and Malmgren ${ }^{2}$ study methods varied from 0.86 to 0.96 for PR images.

Table 2 summarizes the results of frequency (\%) of teeth group most affected with ARR using PR and CBCT scans. The difference was statistically significant to pre-molar maxillary and mandibular group and to molar mandibular group, when compared the frequencies of ARR in $T_{3}$, between PR and CBCT images. The highest presence of ARR by PR was detected in these groups. So, the null hypothesis was rejected. Table 3 shows frequency (\%) of teeth group most affected with ARR using CBCT scans. The maxillary lateral incisors were the teeth most affected by ARR. The second group of teeth most affected by ARR was the mandibular central incisors. The teeth group presenting less ARR was the premolars. Table 4 shows frequency (\%) of ARR according to CBCT scans $\left(\mathrm{T}_{3}\right)$ and effect of extractions. The frequency of teeth with ARR was higher in the group with teeth involved in orthodontic treatments with extractions $(66.7 \%)$ than in the group without extractions (45.2\%). The difference was statistically significant.

Figure 2 shows periapical radiographs of the maxillary lateral incisor suggesting that apical root resorption do not change after finishing the orthodontic tooth movement in long term. Figure 3 shows presence or absence of ARR in central incisor, by PR and CBCT, while Figure 4 shows the same in upper premolar.
Table 1 - Frequency (\%) of ARR after orthodontic treatment $\left(T_{2}\right)$ and past 52 to 288 months follow-up according to PR.

\begin{tabular}{cccc}
\hline Score & $\mathrm{T}_{2}-\mathrm{PR}$ & $\mathrm{T}_{3}-\mathrm{PR}$ & $\mathbf{P}$ \\
\hline 0 & $334(26.3 \%)$ & $306(24.2 \%)$ & $p>0.05$ \\
1 & $654(51.6 \%)$ & $670(53.1 \%)$ & $p>0.05$ \\
\hline 2 & $265(20.9 \%)$ & $277(21.9 \%)$ & $p>0.05$ \\
3 & $14(1.1 \%)$ & $8(0.6 \%)$ & $p>0.05$ \\
4 & $1(0.1 \%)$ & 0 & $p>0.05$ \\
\hline Total & $1,268(100 \%)$ & $1,261(100 \%)$ & $p>0.05$ \\
\hline
\end{tabular}

Table 2 - Frequency (\%) of teeth group most affected with ARR using PR and CBCT scans.

\begin{tabular}{cccc}
\hline Teeth & PR & CBCT & $p$ \\
& $n(\%)$ & $n(\%)$ & \\
\hline Anterior & $286(22.7 \%)$ & $250(19.2 \%)$ & $p>0.05$ \\
\hline Premolars & $136(10.8 \%)$ & $69(5.3 \%)$ & $p<0.05$ \\
\hline Molars & $85(6.7 \%)$ & $56(4.3 \%)$ & $p>0.05$ \\
\hline Anterior & $266(21.1 \%)$ & $230(17.6 \%)$ & $p>0.05$ \\
\hline Premolars & $90(7.1 \%)$ & $41(3.1 \%)$ & $p<0.05$ \\
\hline Molars & $92(7.3 \%)$ & $49(3.8 \%)$ & $p<0.05$ \\
\hline
\end{tabular}

Table 3 - Distribution of teeth most affected with ARR using CBCT scans

\begin{tabular}{|cccc}
\hline Teeth & Absence of ARR & Presence of ARR & Classification \\
\hline $11 / 21$ & $23(19.8 \%)$ & $93(80.1 \%)$ & $3^{\text {rd }}$ \\
\hline $12 / 22$ & $6(5.4 \%)$ & $104(94.5 \%)$ & $1^{\text {st }}$ \\
\hline $13 / 23$ & $63(54.3)$ & $53(45.6 \%)$ & \\
\hline $14 / 24$ & $45(59.2 \%)$ & $31(40.7 \%)$ & $5^{\text {th }}$ \\
\hline $15 / 25$ & $77(66.9 \%)$ & $38(33.0 \%)$ & $2^{\text {nd }}$ \\
\hline $16 / 26$ & $60(51.7 \%)$ & $56(48.2 \%)$ & $4^{\text {th }}$ \\
\hline $31 / 41$ & $14(12.2 \%)$ & $100(87.7 \%)$ & \\
\hline $32 / 42$ & $26(22.4 \%)$ & $90(77.5 \%)$ & \\
\hline $33 / 43$ & $76(65.5 \%)$ & $40(34.4 \%)$ & \\
\hline $34 / 44$ & $66(82.5 \%)$ & $14(17.5 \%)$ & \\
\hline $35 / 45$ & $87(76.3 \%)$ & $27(23.6 \%)$ & $49(42.2 \%)$ \\
\hline $36 / 46$ & $67(57.7 \%)$ & $4 a n d i b l e$ & \\
\hline
\end{tabular}

Table 4 - Frequency (\%) of ARR considering tooth involved in orthodontic treatment with or without extraction, analyzed by $\mathrm{CBCT}\left(\mathrm{T}_{3}\right)$

\begin{tabular}{ccc}
\hline $\begin{array}{c}\text { Enrolled teeth } \\
\text { Orthodontic treatment } \\
\text { without extractions }(n=815)\end{array}$ & Absence of ARR & Presence of ARR \\
\hline $\begin{array}{c}\text { Orthodontic treatment } \\
\text { with extractions }(n=490)\end{array}$ & $163(33.2 \%)$ & $370(45.2 \%)$ \\
\hline$p$ & $p<0.05$ & $327(66.7 \%)$ \\
\hline
\end{tabular}

$p=$ significance of percentage differences 

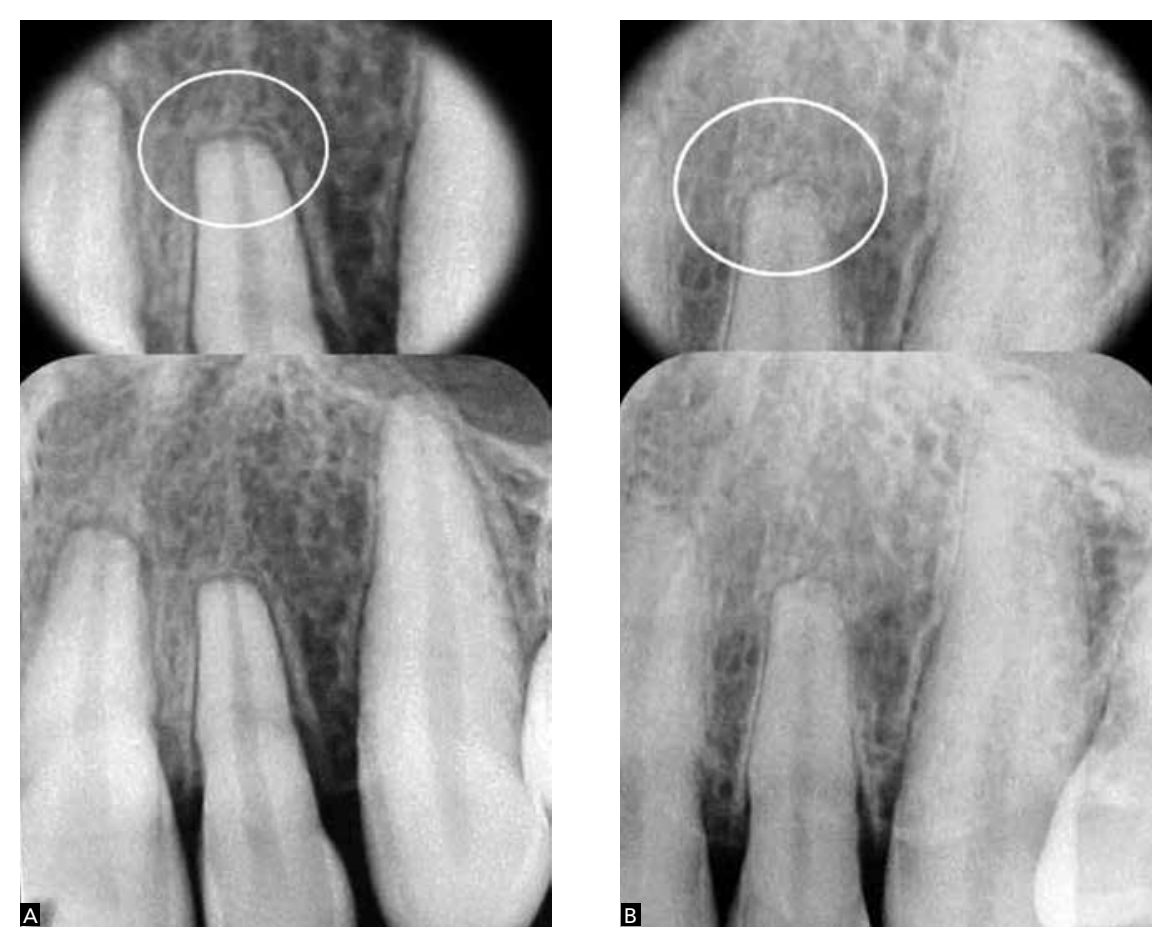

Figure 2 - Periapical radiographs of an upper left lateral incisor presenting the same ARR score after orthodontic treatment (A) and 288 months after treatment (B).
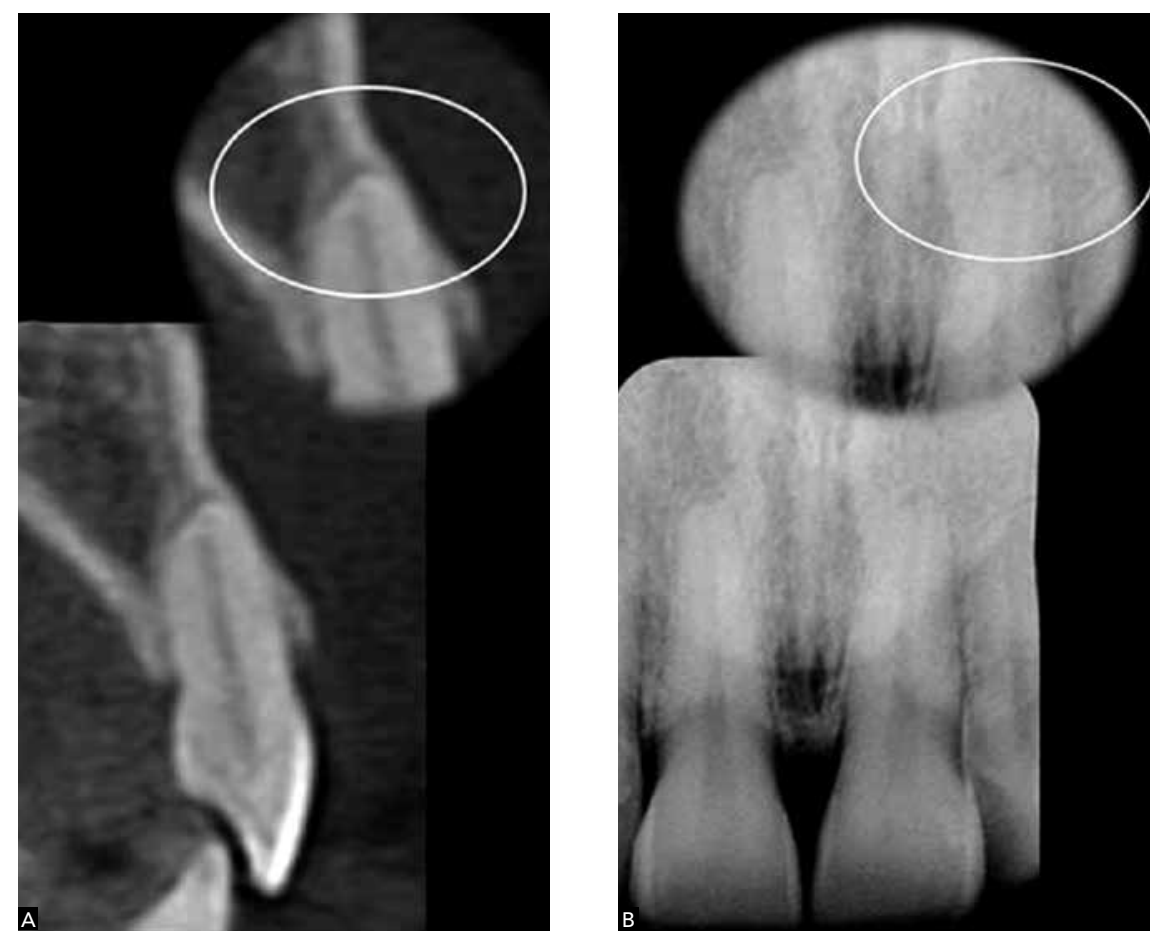

Figure 3 - CBCT scan of a maxillary left central incisor (A) (transverse view) shows more details of apical root resorption than periapical radiography (B). 


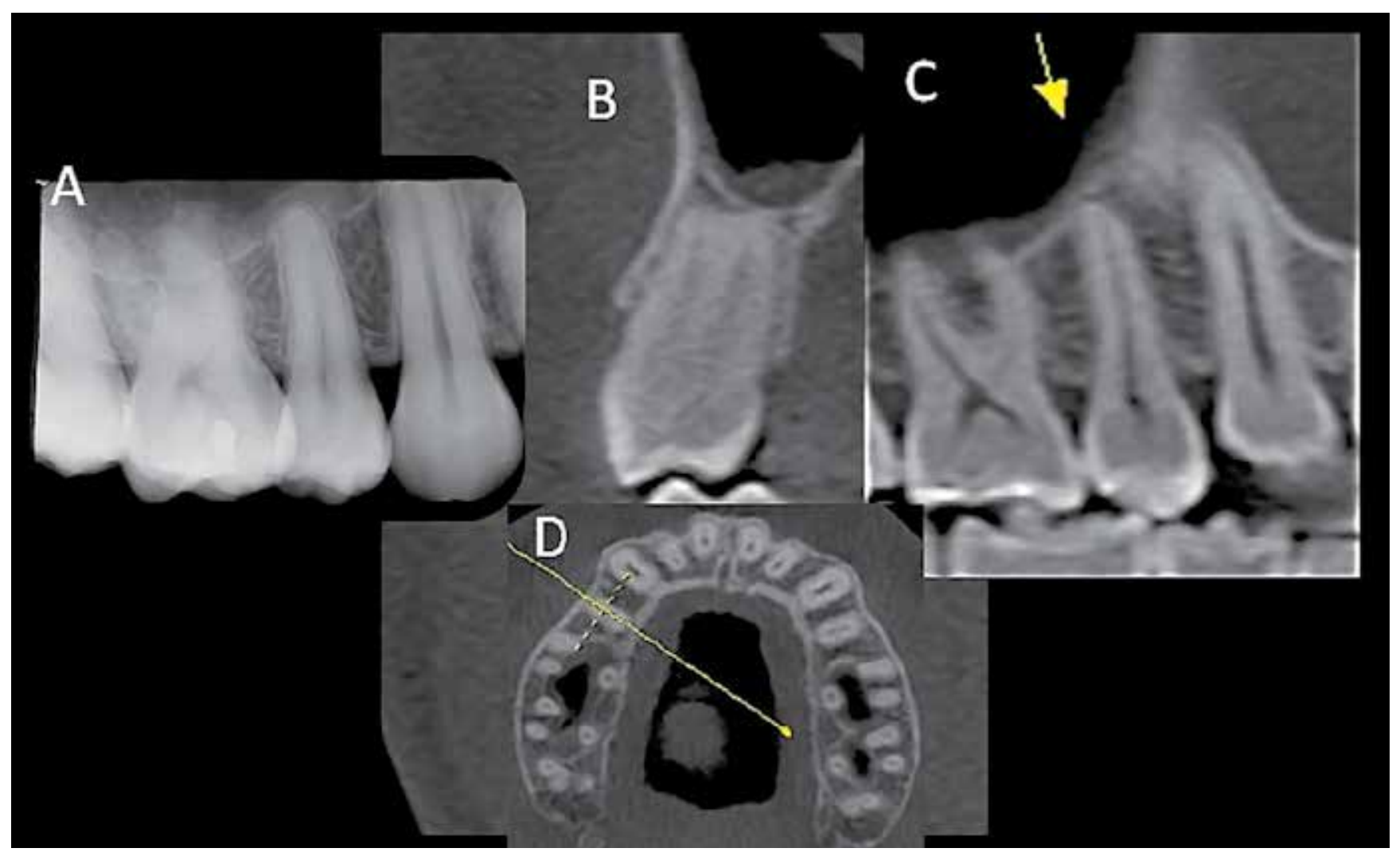

Figure 4 - Periapical radiograph of a maxillary right second premolar shows score 2 according to Levander and Malmgren system (A). The same tooth on CBCT scan presenting absence of ARR (B-D).

\section{DISCUSSION}

The advent of computed tomography brought a true revolution in medical sciences. ${ }^{15-18}$ Particularly in dental specialties, the possibility of acquiring information from three-dimensional images of the maxillofacial region minimized the chances of underestimating lesions, such as ARR, ${ }^{21,24}$ in dental structures. ${ }^{15-18,21-25}$

ARR characterize the loss of tooth structure and occurs due to several factors such as individual biological variability, genetic predisposition, mechanical factors, root morphology, and apical lesions prior to orthodontic treatment. ${ }^{1-6}$ The extent of this resorption after orthodontic treatment influences the prognosis. Harmful consequences for the tooth may occur when severe resorption is present, even if observed in a small percentage and forward to well-planned and conducted orthodontic treatment.

Current knowledge does not allow the orthodontists to identify which patients are vulnerable to serious ARR. In a recent systematic review about ARR associated with orthodontic treatment, Weltman et al ${ }^{1}$ found only 11 suitable studies and the protocols were too variable to undertake a quantitative analysis. This revision reflects the timing of the published research about ARR. No study allowed consistent evidence about the longevity of teeth with severe resorption. ${ }^{28}$

The frequency of ARR, after completion of orthodontic treatment $\left(\mathrm{T}_{2}\right)$ and after 52 to 288 months $\left(\mathrm{T}_{3}\right)$, was determined by PR images (Table 1 ). The most frequent ARR score were 1, which did not show significant difference between $\mathrm{T}_{2}(51.6 \%)$ and $\mathrm{T}_{3}(53.1 \%)$. This study is in agreement with previous findings. ${ }^{9,10}$ Copland and Green ${ }^{9}$ (using lateral cephalometric radiograms) examined 45 individuals to investigate whether ARR in maxillary central incisors associated with orthodontic treatment continues after the end of the active treatment. Mean time between treatment end and final cephalometric radiogram was 2 years 4 months (28 months). When active treatment stopped, further ARR practically stopped, too. 
Remington et $\mathrm{al}^{10}$ conducted a retrospective study (using periapical radiography) to evaluate ARR in 100 patients at a mean 14.1 years (169 months) after orthodontic treatment. They found no apparent changes after appliance removal, except remodeling of rough and sharp edges (Fig 2).

Despite method differences between several studies $^{9,10}$ and our investigation, some important aspects should be analyzed: The mean duration of treatment was 22.9 months; the variation of follow-up time was 52 to 288 months, mean time between treatment end and the final cephalometric radiogram was 1.1 months, range was 0 to 7 months, the evaluation was made according to teeth groups; the scoring system of ARR detected by PR was the one described by Levander and Malmgren, ${ }^{2}$ while the presence or absence of ARR was detected by CBCT images.

The results of $\mathrm{CBCT}$ and $\mathrm{PR}$ images at $\mathrm{T}_{3}$, (52-288 months after treatment) revealed differences between the two imaging methods (Table 2). When comparing the frequencies of $A R R$ in $T_{3}$, the difference was significant for the group of upper and lower premolars, and for the group of mandibular molars. In these dental groups a greater presence of ARR by PR images was detected. The results suggest that PR, due to limitations, tends to overestimate the ARR into posterior teeth groups (Figs 3 and 4). These findings might be assigned to the fact that analyses were made according to teeth groups. In different teeth group, the apical morphological variations, surrounding bone density (thick or thin bone cortex), x-ray angulations, radiographic contrast and overlapping of anatomic structures may affect radiographic interpretations. ${ }^{26}$

Advanced technologies that may potentially aid in establishing diagnoses, such as CBCT, bring up challenges that might only be overcomed when its properties and limitations are fully understood. Developing new software may greatly improve the acquisition and reconstruction of CBCT scans. In this study, a map-reading approach was used to examine all planes of the root apex, as suggested in a recent study $^{27}$ which showed that it promotes the perfect management of CBCT images and might reveal abnormalities not detected in conventional PR. For both imaging methods, extra care was taken to ensure an optimal interpretation environment.
Dudic et $\mathrm{al}^{21}$ compared ARR in 275 teeth of 22 orthodontic patients using panoramic radiography and CBCT and the scoring system develop by Levander and Malmgren. ${ }^{2}$ They found significant differences between the two methods and for all degrees of ARR. Panoramic radiography underestimated ARR after orthodontic treatment. CBCT imaging should be used to help to monitor patients at risk for developing severe root resorption during orthodontic movement. Our results were similar, but we evaluated ARR after a long-term follow-up of orthodontic treatment using PR and CBCT images.

Maxillary lateral incisors (94.5\%) and mandibular central incisors $(87.7 \%)$ were the most affected teeth (Table 3). ARR analysis, using CBCT, forward to the most affected teeth has not been compared with other literature data by a lack of studies. Newman ${ }^{5}$ investigated possible etiological factors of external root resorption and found that maxillary incisors, maxillary premolars, and mandibular second premolars had the greatest incidence of apical resorption. This sequence differed from that found in other studies about root resorption. ${ }^{29,30}$ In the present study, premolar were the least affected teeth by ARR when evaluated through CBCT image. Hemley ${ }^{29}$ through PR showed that the teeth more susceptible to ARR were central incisors (9.1\%). The lower central incisors were more likely to be affected than upper ones. Sharpe et $\mathrm{l}^{30}$ found a higher frequency of ARR using $\mathrm{PR}$ in the central upper central incisors (52.7\%) followed by lower ones (45.7\%).

In this study, it was found that the most affected teeth are the anterior teeth, as demonstrated in other studies. ${ }^{5,9,10,28}$ It might be suggested that a radiographic control of this dental group during and after orthodontic treatment is benefic for detecting of ARR. ${ }^{9}$

Tooth extraction was shown to be a risk factor for ARR during orthodontic tooth movement (Table 4). The frequency of teeth with ARR was higher in the tooth involved in orthodontic treatment with extractions $(66.7 \%)$ than the group without extractions $(45.2 \%)$ analyzed by CBCT $(\mathrm{p}<0.05)$. One explanation for these results may be the fact that, in orthodontic treatment with extractions, extensive movements are needed. Our results are in agreement with those reported by Marques et al, ${ }^{28}$ who found that the main factors directly involved in severe resorption 
were extraction of premolars, triangle-shaped roots and root resorption before treatment. Those authors also found a high prevalence of severe root resorptions in Brazilian patients treated with the edgewise method; differently from our findings.

CBCT is not commonly available in most dental offices. The analysis of the cost-effectiveness of 3D imaging in clinical routine should include the caution with radiation dose, variability of radiation between scanners and the lack of a standard recommended dose in some countries.

Silva et $\mathrm{al}^{22}$ compared the radiation doses of conventional panoramic and cephalometric imaging with the doses of 2 different CBCT units and a multi-slice computed tomography (CT) unit in orthodontic practice. They concluded that conventional imaging still emits the lowest dose of radiation, and when three-dimensional imaging is required in orthodontic practice, CBCT scans should be preferred over CT imaging.
It is presumed that a new technology with potential to assist in diagnosis, such as CBCT, set new challenges until there is a complete understanding of their properties and limitations. New machines with low radiation doses and new software to reduce metal artifacts in CBCT image reconstruction should be developed. Further longitudinal studies should determine the behavior of severe ARR due to orthodontic movement.

\section{CONCLUSION}

PR showed more frequency of ARR in posterior teeth groups when compared with CBCT images. ARR did not change in long-term post treatment.

\section{Acknowledgments}

This study was supported in part by grants from the National Council for Scientific and Technological Development (CNPq grants 302875/2008-5 and CNPq grants $474642 / 2009$ to C.E.). 
1. Weltman B, Vig KW, Fields HW, Shanker S, Kaizar EE. Root resorption associated with orthodontic tooth movement: a systematic review. Am J Orthod Dentofacial Orthop. 2010;137(4):462-76.

2. Levander E, Malmgren O. Evaluation of the risk of root resorption during orthodontic treatment: a study of upper incisors. Eur J Orthod. 1988;10(1):30-8.

3. Al-Qawasmi RA, Hartsfield JK Jr, Everett ET, Flury L, Liu L, Foroud TM, et al. Genetic predisposition to external apical root resorption. Am J Orthod Dentofacial Orthop. 2003:123(3):242-52.

4. Harris EF, Kineret SE, Tolley EA. A heritable component for external apical root resorption in patients treated orthodontically. Am J Orthod Dentofacial Orthop. 1997:111(3):301-9.

5. Newman WG. Possible etiologic factors in external root resorption. Am J Orthod. 1975:67(5):522-39.

6. McLaughlin KD. Quantitative determination of root resorption during orthodontic treatment [abstract]. Am J Orthod. 1964:50(2):143

7. Consolaro A, Consolaro MF. The orthodontic root resorption is inflammatory, the phenomenon are genetically regulated although not hereditarily transmitted. Rev Dental Press Ortod Ortop Facial. 2009;14(4):25-32.

8. Levander E, Malmgren $\mathrm{O}$, Eliasson S. Evaluation of root resorption in relation to two orthodontic treatment regimes. A clinical experimental study. Eur J Orthod. 1994;16(3):223-8.

9. Copeland S, Green L J. Root resorption in maxillary central incisors following active orthodontic treatment. Am J Orthod. 1986:89(1):51-5

10. Remington DN, Joondeph DR, Artun J, Riedel RA, Chapko MK. Long-term evaluation of root resorption occurring during orthodontic treatment. Am J Orthod Dentofacial Orthop. 1989:96(1):43-6.

11. Ambrose J. Computerized transverse axial scanning (tomography): Part 2 Clinical application. Br J Radiol. 1973:46:1023-47.

12. Hounsfield GN. Computerized transverse axial scanning (tomography): Part 2. Clinical application. Br J Radiol. 1973;46:1016-22.

13. Arai Y, Tammisalo E, Hashimoto K, Shinoda K. Development of a compact computed apparatus for dental use. Dentomaxillofac Radio. 1999(28):245-8.

14. Mozzo P, Procacci C, Tacconi A, Martini PT, Andreis IA. A new volumetric CT machine for dental imaging based on the cone-beam technique: preliminary results. Eur Radiol. 1998:8:1558-64

15. Scarfe WC, Farman AG, Sukovic P. Clinical applications of cone-beam computed tomography in dental practice. J Can Dent Assoc. 2006:72(1):75-80.

16. Farman AG. Applying DICOM to dentistry. J Digit Imaging. 2005;18(1):23-7.

17. Farman AG, Scarfe WC. Development of imaging selection criteria and procedures should precede cephalometric assessment with cone-beam computed tomography. Am J Orthod Dentofacial Orthop. 2006:130(2):257-65
18. De Vos W. Casselman J, Swennen GRJ. Cone-beam computerized tomography $(\mathrm{CBCT})$ imaging of the oral and maxillofacial region: a systematic review of the literature. Int J Oral Maxillofac Surg. 2009:38(6):609-25

19. Spence TM. A prospective study of apical root resorption during orthodontic treatment and into retention. Am J Orthod Dentofac Orthop 2001;119(4):A1

20. Reukers E, Sanderink G, Kuijpers-Jagtman AM, van't Hof M. Assessment of apical root resorption using digital reconstruction. Dentomaxillofac Radiol. 1989;27(1):25-9

21. Dudic A, Giannopoulou C, Leuzinger M, Kiliaridis S. Detection of apical root resorption after orthodontic treatment by using panoramic radiography and cone-beam computed tomography of super-high resolution. Am J Orthod Dentofacial Orthop. 2009;135(4):434-7.

22. Silva MA, Wolf U, Heinicke F, Bumann A, Visser H, Hirsch E. Conebeam computed tomography for routine orthodontic treatment planning: a radiation dose evaluation. Am J Orthod Dentofacial Orthop. 2008:133(5):640.e1-5

23. Estrela C, Bueno MR, Leles CR, Azevedo B, Azevedo JR. Accuracy of cone beam computed tomography and panoramic and periapical radiography for detection of apical periodontitis. J Endod. 2008:34(3):273-9.

24. Estrela C, Bueno MR, Alencar AH, Mattar R, Neto JV, Azevedo BC, Estrela CRA. Method to evaluate inflammatory root resorption by using cone beam computed tomography. J Endod. 2009:35(11):1491-7.

25. Kau CH, Bozic M, English J, Lee R, Bussa H, Ellis RK. Cone-beam computed tomography of the maxillofacial region - an update. Int J Med Robot. 2009:5(4):366-80

26. Huumonen S, Orstavik D. Radiological aspects of apical periodontitis. Endod Topics. 2002:1(1):3-25

27. Bueno MR, Estrela C, Figueiredo JAP, Azevedo BC. Map-reading strategy to diagnose root perforations near metallic intracanal posts by using cone beam computed tomography. J Endod. 2011;37(1):85-90.

28. Marques LS, Ramos-Jorge ML, Rey AC, Amond MC, Ruellas ACO. Severe root resorption in orthodontic patients treated with the edgewise method: prevalence and predictive factors. Am J Orthod Dentofacial Orthop. 2010;137(3):384-8

29. Hemley $\mathrm{S}$. The incidence of root resorption of vital permanent teeth J Dent Res. 1941:20(2):133

30. Sharpe W, Reed B, Subtelny JD, Poison A. Orthodontic relapse, apical root resorption, and crestal alveolar bone levels. Am J Orthod Dentofacial Orthop. 1987:91(3):252-8 